\title{
A Pediatric Opportunity in Adolescents to Prevent Adult Heart Attacks
}

\author{
David S. Schade1, Shirley Murphy², Vernat Exil ${ }^{3}$, R. Philip Eaton ${ }^{4}$ \\ ${ }^{1}$ Endocrinology and Metabolism, University of New Mexico School of Medicine, Albuquerque, New Mexico, USA \\ ${ }^{2}$ Pediatrics, University of New Mexico School of Medicine, Albuquerque, New Mexico, USA \\ ${ }^{3}$ Pediatric Cardiology, University of New Mexico School of Medicine, Albuquerque, New Mexico, USA \\ ${ }^{4}$ Endocrinology and Metabolism, University of New Mexico School of Medicine, Albuquerque, New Mexico, USA \\ Email: dschade@salud.unm.edu
}

How to cite this paper: Schade, D.S., Murphy, S., Exil, V. and Eaton, R.P. (2018) A Pediatric Opportunity in Adolescents to Prevent Adult Heart Attacks. World Journal of Cardiovascular Diseases, 8, 85-101. https://doi.org/10.4236/wjcd.2018.82009

Received: November 3, 2017

Accepted: January 30, 2018

Published: February 2, 2018

Copyright (c) 2018 by authors and Scientific Research Publishing Inc. This work is licensed under the Creative Commons Attribution International License (CC BY 4.0).

http://creativecommons.org/licenses/by/4.0/

cc) (†) Open Access

\begin{abstract}
Importance: Cardiovascular disease is the number one cause of death in the adult population, greater than all cancers combined. When a heart attack or stroke occurs, many individuals have no advance warning, thus making prevention difficult. Cardiovascular disease begins early, i.e., in the developing fetus, and progresses throughout childhood and adolescence, such that it is identifiable both radiographically and ultrasonographically in the adolescent. Observations: There are multiple lines of evidence that atherosclerosis is present in the pediatric population. This evidence is based on autopsy studies in accident victims, coronary artery calcium scoring and carotid intermedia thickness measurements, intravascular ultrasound studies of hearts transplanted from teenage accident victims, and wartime casualties in young males. Multiple studies of cardiovascular risk factors (e.g., hypertension, obesity, insulin resistance, glucose intolerance and hyperlipidemia) have emphasized their importance in contributing to the pathogenesis of atherosclerosis. With the recent increase of obesity in the pediatric population, these risk factors will assume increasing importance in the development of clinical cardiovascular disease in the adult population. Prevention of atherosclerosis will require measuring a lipid profile in adolescents and initiating intervention to reduce the triglyceride and LDLc concentration. Education of both the adolescent at risk and his/her family will be necessary. Lifestyle changes are paramount. Hyperlipidemic medication should be reserved for individuals with severe lipid abnormalities. Conclusion and Relevance: Atherosclerotic changes of arteries begin during gestation and progress throughout the pediatric years into adulthood. Pediatricians' contribution to reducing the progression of atherosclerosis in their patients can have major effects in controlling this epidemic in adults. Education of adolescents and their parents concerning
\end{abstract}


a healthy lifestyle is paramount to a successful cardiovascular disease prevention program.

\section{Keywords}

Atherosclerosis, Adolescence, Myocardial Infarction, Cardiovascular, Pediatrics

\section{Introduction}

Major advances in medical technology and therapeutics in the last decade have resulted in prolongation of life in heart attack and stroke victims. However, these advances have not decreased the prevalence of atherosclerotic disease, which still remains the number one cause of death in the adult population [1]. Atherosclerosis begins in the fetal period, progresses throughout adolescence, and becomes clinically manifested in the adult population. Appropriate pediatric intervention during adolescence may not only prevent the further development of atherosclerotic plaques but may also stabilize plaques that have previously formed [2].

There is an increased incidence of obesity in the pediatric population. As the BMI increases, the risk of coronary heart disease in adulthood increases [3] [4]. By the time adolescence is reached, $50 \%$ of obese adolescents will have radiographically identifiable plaques in their coronary arteries (Figure 1) [5]. The process of atherosclerosis begins during fetal development when fatty streaks are present in arteries and is most pronounced in fetuses from mothers who are hypercholesterolemic during their pregnancy (Figure 2) [6] [7]. These fatty streaks have been shown to contain both native LDLc and oxidized LDLc as well as macrophage derived cellular products [6]. Following birth, these lesions increase significantly between ages 1 year and 3 years and are identifiable both radiographically and ultrasonographically by the teenage years [5] [6]. Histological studies demonstrate a progressive increase in plaque formation and maturation from childhood through adolescence and progression into adulthood (Figure 3) [8].

\section{Discussion}

Atherosclerosis is a devastating disease that often occurs unexpectedly in the prime of life when productivity of the individual is at its peak. Approximately, fifty percent of the time it is silent (painless), although even silent myocardial infarction is associated with significant morbidity and mortality [9]. Its cost to society and the health care system is staggering and thus it directly and indirectly affects all U.S. citizens through health care system premiums and lost work productivity. Recent national data indicate, for the first time in 16 years, that the anticipated lifespan in the U.S. has declined, primarily because the mortality 


\section{Progression of Atherosclerosis in Childhood}

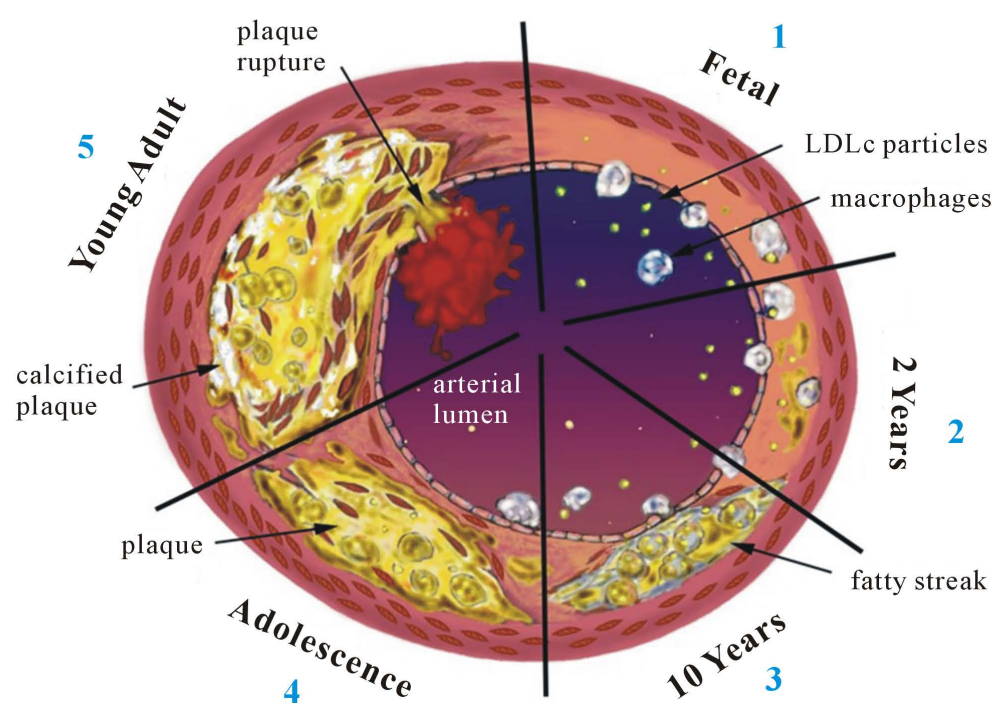

Figure 1. Schematic sequence of the progression of atherosclerosis during the pediatric years. Atherosclerosis begins during gestation, continues throughout childhood and adolescence, when finally it becomes clinically manifest in adulthood.

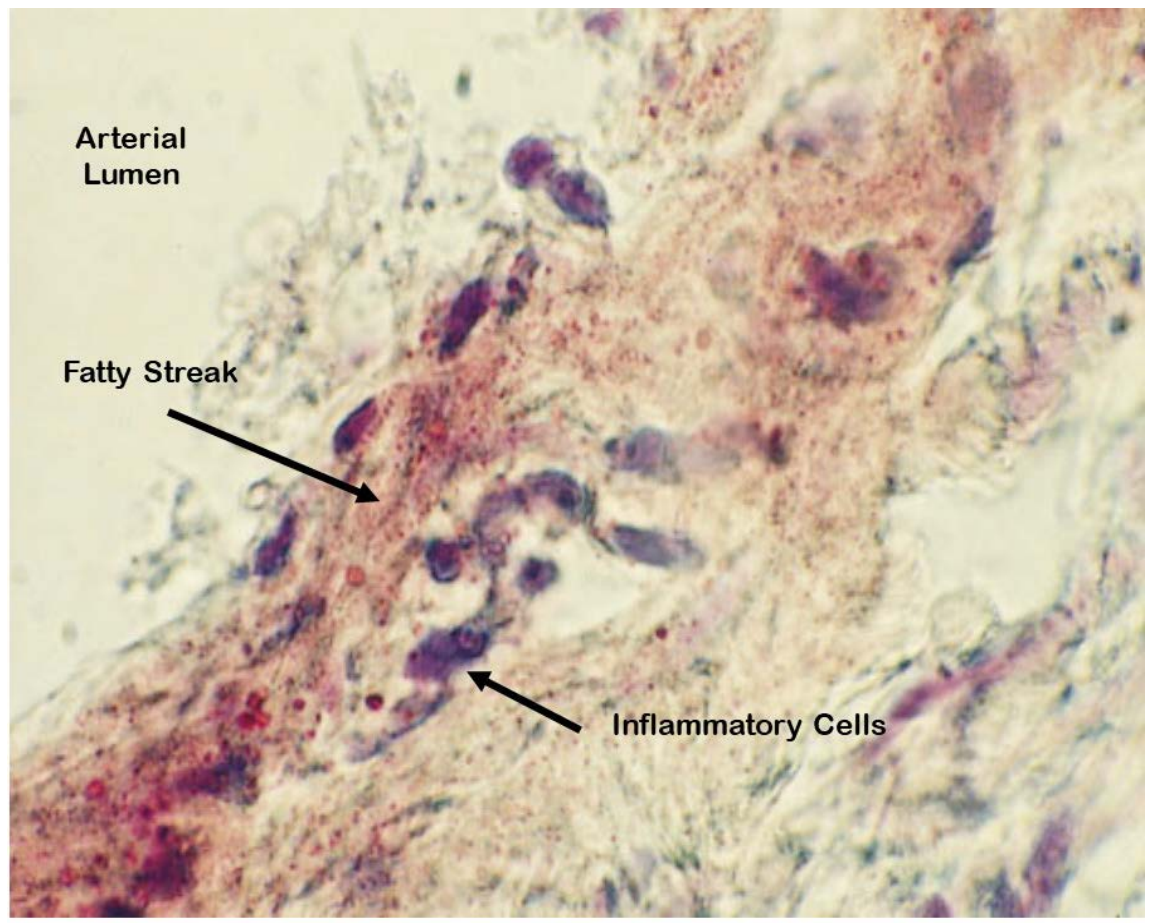

Figure 2. Presence of intimal lipid accumulations in a fetal aorta stained with oil red O. High magnification of a fatty streak containing substantial amounts of lipid (magnification: 2250×). Adapted from Napoli et al. [7].

from atherosclerotic cardiovascular disease (ASCVD) has increased in the younger age groups [10]. To put the magnitude of this health challenge in numerical perspective, approximately 600,000 individuals in the U.S. die each year 


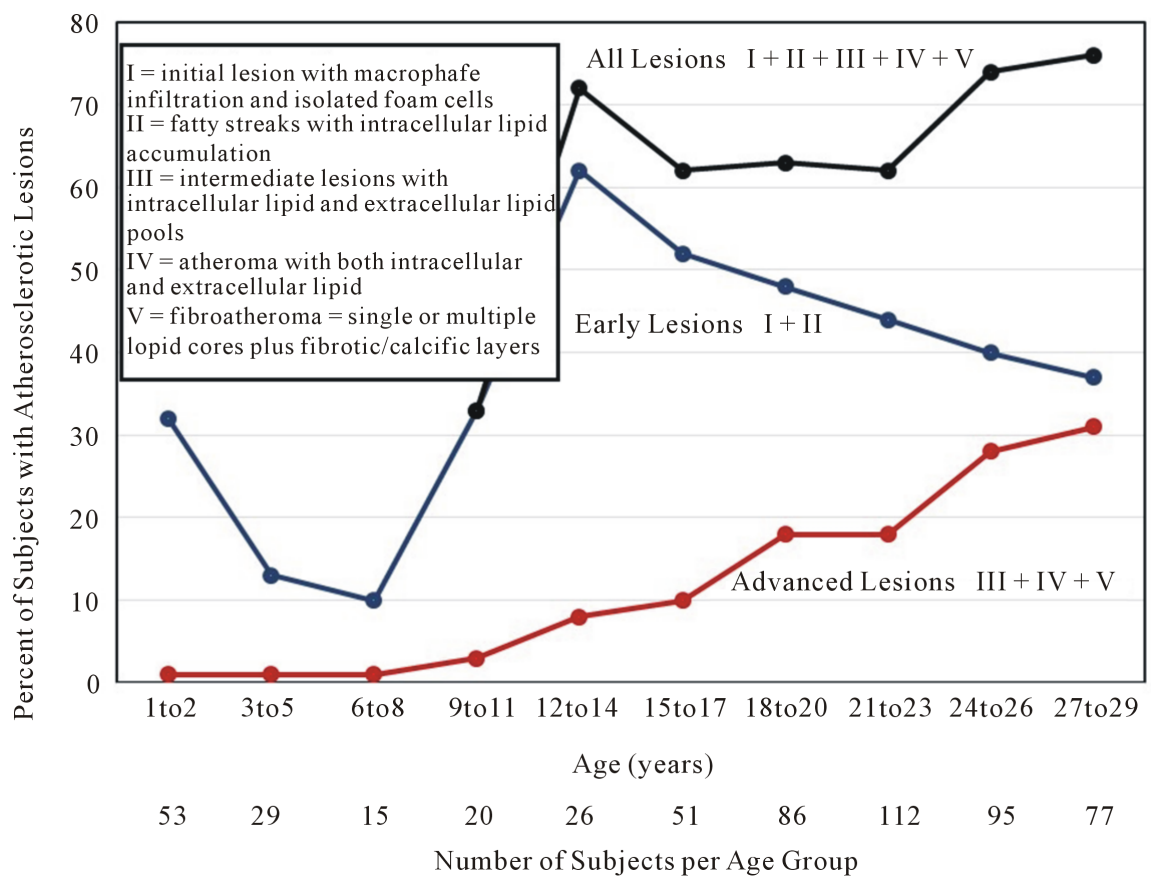

Figure 3. Percentages of individuals at different age groups with identifiable atherosclerotic plaques. By early adolescence, two thirds of the population have atherosclerotic plaques. With increasing age, early lesions (I \& II) are replaced by more advanced lesions [fatty streaks (III) progress to potentially hazardous fibroatheromatous plaques (IV \& V)]. Adapted from Stary [8].

from atherosclerotic cardiovascular disease (ASCVD).

One encouraging fact is that atherosclerosis is predictable from readily measured risk factors, providing physicians with addressable parameters. Risk factors persist unless they are modified, thereby leading to a significant reduction in ASCVD events in the adult patient population [11]. Even in the setting of increased risk from atherosclerotic mediated inherited genes, aggressive reduction of environmental risk factors will reduce future risks for atherosclerosis by $50 \%$ [12]

The Bogalusa Heart Study was a long-term epidemiological study of cardiovascular risk factors in children from birth to 26 years of age [13]. This biracial population (64\% white, $36 \%$ black) consisted of all children and young adults living in Bogalusa, Louisiana (population 22,000). Cross-sectional surveys were done every 2 to 3 years to monitor cardiovascular risk factors and other demographic and anthropometric data. In children, adolescence and young adults, the average LDLc was significantly above the 50 to $70 \mathrm{mg} / \mathrm{dl}$ expected at birth (Table 1) [14]. The table demonstrates the tendency for LDLc to increase with age and HDLc to decrease. Adverse lipid profiles tend to track consistently over time from childhood to adulthood, particularly for LDLc [15]. This long-term cumulative burden of LDLc from childhood to adulthood is associated with carotid artery intima-media thickness and increased risk for cardiovascular events [16]. This cumulative relationship among risk factors, atherosclerosis, and age, has 
Table 1. Effect of age, race, and gender on serum lipoproteins.

\begin{tabular}{ccccc}
\hline & $\begin{array}{c}\text { White males } \\
(n=1153)\end{array}$ & $\begin{array}{c}\text { Black males } \\
(n=585)\end{array}$ & $\begin{array}{c}\text { White females } \\
(n=1262)\end{array}$ & $\begin{array}{c}\text { Black females } \\
(n=623)\end{array}$ \\
\hline VLDL-C (mg/dl) & & & & \\
$5-10$ years & $6 \pm 7$ & $5 \pm 4$ & $7 \pm 7$ & $6 \pm 8$ \\
$11-18$ years & $11 \pm 10$ & $8 \pm 7$ & $11 \pm 8$ & $9 \pm 7$ \\
$19-26$ years & $18 \pm 15$ & $9 \pm 7$ & $14 \pm 12$ & $10 \pm 7$ \\
LDL-C (mg/dl) & & & & $92 \pm 21$ \\
$5-10$ years & $88 \pm 23$ & $87 \pm 21$ & $94 \pm 23$ & $94 \pm 24$ \\
$11-18$ years & $88 \pm 25$ & $91 \pm 24$ & $92 \pm 25$ & $108 \pm 31$ \\
$19-26$ years & $116 \pm 31$ & $99 \pm 29$ & $112 \pm 34$ & \\
HDL-C (mg/dl) & & & & $74 \pm 15$ \\
$5-10$ years & $68 \pm 17$ & $74 \pm 18$ & $64 \pm 18$ & $68 \pm 21$ \\
$11-18$ years & $57 \pm 20$ & $68 \pm 20$ & $59 \pm 20$ & $59 \pm 25$ \\
$19-26$ years & $44 \pm 21$ & $61 \pm 20$ & $51 \pm 20$ &
\end{tabular}

Serum levels (mean $\pm \mathrm{SD}$ ) of lipoprotein cholesterol fractions in children, adolescents, and young adults: from the Bogalusa Heart Study. Adapted from Srinivasan et al. [14].

also been examined in autopsy studies from individuals (ages 2 through 39 years) who died from various causes, primarily trauma [17] [18]. This study demonstrated that the extent of fatty streaks increases with age [17]. In addition, subjects with $0,1,2,3,4$ risk factors had, respectively, $1.3 \%, 2.5 \%, 7.9 \%$, and $11.0 \%$ fatty streaks in the coronary arteries $(\mathrm{p}<0.01$ for trend). The authors of this study conclude that, "As the number of cardiovascular risk factors increase, so does the severity of asymptomatic coronary and aortic atherosclerosis in young people". These landmark studies further support the need for aggressive intervention in the adolescence period.

Since LDLc is the critical component in the formation of atherosclerotic plaques, an appropriate question to ask is "what is the optimal LDLc concentration that should be the goal of treatment to prevent atherosclerosis without causing adverse effects?" Expert opinions differ markedly on this subject. The prominent cardiologist, Dr. Eugene Braunwald stated in response to learning that the European Society of Cardiology had adopted $<70 \mathrm{mg} / \mathrm{dl}$ for very-high-risk adults as the goal stated "the goal should be less than $50 \mathrm{mg} / \mathrm{dl}$ - anything above $50 \mathrm{mg} / \mathrm{dl}$ is toxic" [19]. Another prominent cardiologist, Dr. James O'Keefe, wrote an article entitled "Optimal Low Density Lipoprotein Cholesterol is 50 to $70 \mathrm{mg} / \mathrm{dl}$ " [20].

In contrast, the American Academy of Pediatrics' Guidelines indicate that an LDLc of $110 \mathrm{mg} / \mathrm{dl}$ or below is acceptable [21]. In diabetic patients, the American Diabetes Association, which considers diabetes as a "coronary heart disease equivalent", recommends an LDLc concentration $<100 \mathrm{mg} / \mathrm{dl}$ in diabetic children [22]. Recognizing that there are no randomized controlled trials of sufficient 
size nor duration in the pediatric population to answer the question stated above, there are ten lines of evidence supporting an LDLc of $110 \mathrm{mg} / \mathrm{dl}$ or less as the minimally acceptable LDLc concentration in the adolescent population.

The first line of evidence is the fact that individuals are born with an LDLc between 50 and $70 \mathrm{mg} / \mathrm{dl}$ (20]. Thus, this concentration should be considered "normal", at least for this young age group. The second line of evidence is based on the observation that every cell in the body has the ability to synthesize sufficient cholesterol to meet its cellular needs [23]. Cellular uptake of circulating cholesterol from LDLc is not required. This concern was originally raised when statin therapy dramatically lowered LDLc concentrations. However, several studies demonstrated that significant reduction in LDLc by statins does not inhibit the adrenal's production of cortisol or the testicular production of testosterone, at least in adults [24]. Third, multiple statin studies utilizing either atorvastatin or rosuvastatin in high dosages have observed many adult volunteers whose plasma LDLc levels were reduced below $70 \mathrm{mg} / \mathrm{dl}$. These studies demonstrated that these individuals had fewer cardiovascular events than similar volunteers whose LDLc was not reduced below $70 \mathrm{mg} / \mathrm{dl}$ [25]. Even volunteers on statins with LDLc concentrations below $40 \mathrm{mg} / \mathrm{dl}$ had better outcomes with no increase in adverse effects [26]. Fourth, the recent availability of PCSK9 inhibitors (proprotein convertase subtilisin-kexin type 9) have resulted in a third of the volunteers in these clinical trials obtaining LDLc levels below $50 \mathrm{mg} / \mathrm{dl}$. In a meta-analysis of these ten trials, individuals with these low LDLc levels have fewer cardiovascular events without additional adverse events [27]. Fifth, the Tarahumara Indians of Mexico are a tribe favoring a very low cholesterol containing diet and enhanced exercise. Their LDLc cholesterol approximates $70 \mathrm{mg} / \mathrm{dl}$ unless challenged with a Westernized diet [28]. Their incidence of cardiovascular disease is correspondently low. Sixth, studies of individuals whose genetic makeup include genes which result in unusually low levels of LDLc have reduced cardiovascular disease [29]. Seventh, a meta-analysis of many statin trials have concluded that there is a direct relationship between LDLc reduction and the reduction of cardiovascular disease [25]. For each mmol reduction in LDLc concentration $(\sim 39 \mathrm{mg} / \mathrm{dl})$, there is a corresponding $\sim 20 \%$ reduction in cardiovascular events. Of particular importance is the fact that this relationship is continuous over the entire range of observed LDLc and does not diminish as the LDLc is progressively reduced. Eighth, there are individuals born with defective or absent PCSK9 protein. The absence of this protein decreases the degradation of the LDL hepatic receptor resulting in decreased circulating LDLc levels. One of the described individuals was a 23-year-old healthy, fertile college graduate with a circulating LDLc concentration of $14 \mathrm{mg} / \mathrm{dl}$ [30]. She has experienced no adverse reactions from her very low LDLc concentration. Ninth, aggressive LDLc lowering treatment of children with homozygous familial hypercholesterolemia has been successful in reducing their rate of cardiovascular disease [31]. If left untreated, death from a cardiovascular event often occurs before the age of 20 years. 
Tenth, the most common concentration of LDLc in 131,000 patients presenting to the emergency room with a cardiovascular event is $90 \mathrm{mg} / \mathrm{dl}$, above the LDLc level of 65 to $70 \mathrm{mg} / \mathrm{dl}$ at which reversal occurs [2] [32]. Because extensive safety data are not available for low LDLc concentrations in the pediatric population, a conservative approach to LDLc lowering would be a concentration of $110 \mathrm{mg} / \mathrm{dl}$ or below in this age group [21] [33].

\section{Pathophysiology}

Since LDL derived cholesterol may result in the development of fatty streaks and the ultimate formation of atherosclerotic plaques, its beneficial purpose in human physiology is often not evident. During early fetal development, the fetal adrenal gland greatly hypertrophies in order to produce large quantities of dehydroepiandrosterone sulfate (a steroid which serves as a precursor for placental estrogen secretion) [34]. Large quantities of estrogens are necessary to maintain a normal pregnancy. At approximately three months, the fetal gland requires cholesterol to manufacture dehydroepiandrosterone sulfate. Studies in fetal adrenal glands have demonstrated that about half of the cholesterol is obtained from circulating LDL cholesterol and half from denovo synthesis by the fetal adrenal gland [35]. Toward late pregnancy, the fetal adrenal gland involutes and becomes greatly reduced in size and function when the placenta is large enough to produce sufficient estrogen without adrenal support. During this time, the fetal circulating LDLc concentration also declines so that at birth the concentration is between 50 and $70 \mathrm{mg} / \mathrm{dl}[20]$.

Atherosclerosis requires two pathophysiological events that often occur simultaneously in the arterial system (Figure 1). The first is an excess of circulating cholesterol such that its deposition in the arteries exceeds its subsequent arterial removal by the activity of high-density lipoprotein (HDLc) [36]. Cholesterol is primarily distributed by circulating low-density lipoprotein and its precursors ( 90\%) (LDLc), with additional contributions from very low-density lipoprotein (VLDLc) remnants. The latter are present in elevated concentrations in patients with hypertriglyceridemia [37]. Cholesterol containing lipoprotein particles diffuse through the arterial endothelium, infiltrate the subendothelium, become oxidized, and are taken up by macrophage surface receptors [38]. The second requirement for the development of atherosclerosis is an excess of macrophages in the arterial wall tissue that engulf the oxidized LDLc and then coalesce into a "fatty streak". This occurs when the endothelium is "inflamed" as a result of numerous pathological states such as obesity, hyperglycemia, insulin resistance, and hypertension [39] [40]. The injured endothelium secretes adhesion macromolecules that further attract additional circulating monocytes (macrophage precursors) to adhere to the endothelium. Macrophages that are involved in fatty streak formation also secrete inflammatory cytokines, thereby initiating a cascade of events that lead to arterial smooth muscle cell migration around a fatty streak, development of a fibrous cap internally covering a 
developing plaque, and the formation of thrombotic substances in the plaque itself (along with cholesterol). In this microenvironment of plaque formation, there is also attraction of other inflammatory white cells, and secretion of metalloproteinase enzymes that dissolve the fibrous tissue cap. Eventually, a fibrous cap may weaken and rupture, causing its thrombotic contents to enter the intravascular space, attracting platelets and other clotting factors. An occluding blood clot is usually the end result, causing a myocardial infarction (or stroke) with dire consequences to the affected individual.

The liver removes most of the circulating LDLc particles, but when LDLc is present in excessive amounts, it circulates in elevated concentrations and diffuses into various tissues including systemic arteries, leading to its oxidation, internalization in macrophages, and subsequent participation in fatty streaks and plaque formation [38]. The continuous development and removal of atherosclerosis is a balance between the deposition of cholesterol into atherosclerotic plaques (from LDLc and other atherosclerotic particles) and their removal by high density lipoprotein particles (HDLc). However, there is a poor correlation between the concentration of HDLc in the circulation and its ability to remove cholesterol from the cell [41]. Oxidation of HDL reduces its ability to remove cholesterol from macrophage derived foam cells [42]. This may also be the reason that raising HDLc concentration by pharmaceutical agents has not yet shown to be of benefit in reducing cardiovascular events [43]. Thus, reducing LDLc concentration is the most effective direct approach to reducing the formation of atherosclerotic plaques. This has been documented in many studies utilizing different methods to lower LDLc concentration [44].

\section{Clinical Presentation}

Because atherosclerosis is usually a silent disease in childhood, the physician must make an extra effort to identify individuals in whom it will be a significant risk. Patients with a positive family history of early cardiovascular events or the presence of atherosclerotic risk factors should be particularly suspect [45]. Given that all adolescents are at risk, physicians and health care providers of young patients must assess all conventional risk factors, such as smoking, hypertension, obesity, diabetes, and hyperlipidemia. Obesity stands out as a particularly hazardous risk. In a nation-wide population based study, Twig at al report that body-mass index (BMI) in 2.3 million adolescents (ages 17 and 18 years) correlated with development of cardiovascular disease [46]. A BMI in the $50^{\text {th }}$ to $70^{\text {th }}$ percentile (within the accepted normal range), during adolescents was associated with increased cardiovascular events and all-cause mortality during 40 years of follow-up. Risk of death from coronary artery disease, stroke, sudden death, and total cardiovascular causes were elevated with $\mathrm{BMI}$ as low as $22.5 \mathrm{Kg} / \mathrm{m}^{2}$. Risks for total cardiovascular events including death are further increased among extremely obese individuals. This finding represents a medical challenge, as normal BMI is usually considered between 18.5 and $25 \mathrm{Kg} / \mathrm{m}^{2}$ (lower in Oriental 
individuals).

\section{Assessment and Diagnosis}

In the pediatric population, the clinical exam may be unremarkable, even in the patient with significant atherosclerosis. Obese patients may have acanthosis nigracans as a physical sign of insulin resistance. Hypertension may be present. Eruptive xanthomas are an important sign of severe hypertriglyceridemia. Tendon xanthomas and xanthelasmas indicate significant hypercholesterolemia and may suggest the diagnosis of familial homozygous or heterozygous hypercholesterolemia.

Baseline laboratory tests, including a lipid profile, will provide total cholesterol, non HDL cholesterol, HDL, triglycerides, and LDL, and should be routinely done in early adolescence. This approach is in agreement with the National Heart, Lung, and Blood institute and the American Academy of Pediatrics guidelines for cardiovascular risk reduction in children and adolescents which recommends universal screening for blood cholesterol levels at ages 9 to 11 years and 17 to 21 years of age [47] [48]. Lipoprotein (a) measurement can be done in select individuals to assess a genetic predisposition to atherosclerosis [49] [50]. High sensitivity C-reactive protein (hsCRP) is a sensitive test for systemic inflammation. A hemoglobin A1C is a good indication of glucose tolerance, prediabetes, or diabetes. A fasting glucose and insulin level will permit assessment of hyperglycemia and insulin resistance. The above tests and approaches often lack the necessary sensitivity and specificity to detect subclinical disease or the early stages of atherosclerotic disease in pre-adolescence and adolescence. Although quantification of risk factors provide a good indication of future ASCVD, non-invasive imaging should be made available early, as it provides additional verification of the presence of progressive plaque development. Carotid intima medial thickness is now widely available, non-invasive, and correlates significantly with coronary atherosclerosis [51] [52]. When utilized from childhood through middle age, it is directly related to the presence and magnitude of cardiovascular risk factors [16]. This positive relationship is maintained throughout life and has been shown to be present even in the elderly population [53]. An alternative non-invasive imaging technique which images abnormal coronary arteries directly is coronary artery calcium scanning but it does involve a small dose of radiation [5] [54]. This dose is equivalent to living in Denver for three months. Other noninvasive approaches have also been described [55] [56].

\section{Treatment}

A major effort should be focused on maintaining normal body weight with exercise and healthy diets (Figure 4). Patients and families should be encouraged to take advantage of a variety of local programs in their communities and their schools to assist with their goal. Involvement of parents and entire families are essential with promotion of a Mediterranean type of diet encouraged [57]. 
Diagnosis and Treatment Plan for Adolescent LDLc Goal of $<110 \mathrm{mg} / \mathrm{dl}$

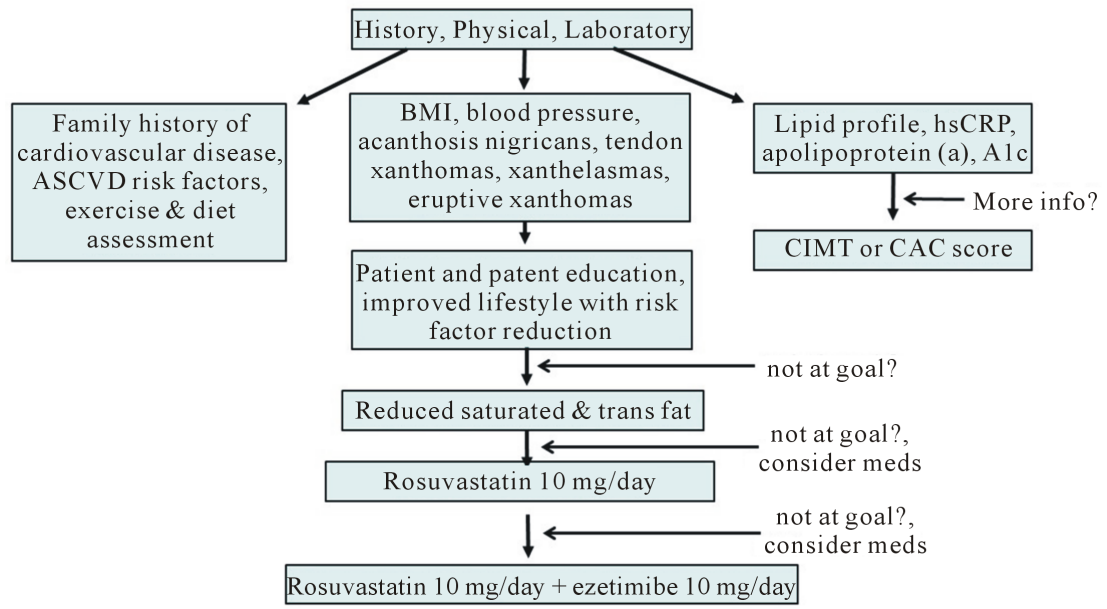

Figure 4. Proposed diagnosis and treatment plan for adolescents to reverse atherosclerosis and prevent clinical cardiovascular events in adults.

If lifestyle changes do not result in an LDLc of $<110 \mathrm{mg} / \mathrm{dl}$, then we recommend that medical therapy should be considered in the early adolescent years. Statins have been prescribed to children with homozygous familial hypercholesterolemia for more than 10 years without serious adverse effects, resulting in a significant decline in cardiovascular disease [58] [59]. The two currently available most potent generic statins are atorvastatin and rosuvastatin. We recommend using $10 \mathrm{mg} /$ day of rosuvastatin, which is more potent than atorvastatin at low dosages. Since the side effects of statins are dependent on their plasma concentration, utilizing only the lowest dose will avoid major adverse events [60].

Drugs that increase the LDLc hepatic receptor to lower circulating LDLc (including statins) may increase glucose intolerance. If the individual is prediabetic, these medications may move the fasting glucose into the diabetic range [61]. However, this small change may be avoided with improvements in lifestyle. If the $\mathrm{LDLc}$ goal of $<110 \mathrm{mg} / \mathrm{dl}$ is not achieved, adding ezetimibe at $10 \mathrm{mg} /$ day is a reasonable addition. This medication has been used in children for over $31 / 2$ years without adverse effects [62]. Ezetimibe blocks $50 \%$ of the cholesterol that is absorbed by the gut by specifically inhibiting the intestinal cholesterol receptor but does not interfere with the absorption of other fats, proteins, or carbohydrates [63]. It is very effective is lowering LDLc (20\% to $28 \%$ ) and is additive to the concurrent use of statins.

Monitoring of risk factors should be part of routine clinic visits. For glucose intolerance (prediabetes), achieving normal weight is essential. If the $\mathrm{A} 1 \mathrm{C}$ exceeds $6.0 \%$, metformin is a logical choice, as data from adults indicate that atherosclerosis is accelerated in the prediabetic state [64]. Patients with diabetes are particularly at high risk for cardiovascular disease [65]. Triglycerides should be less than $150 \mathrm{mg} / \mathrm{dl}$ and LDLc less than $110 \mathrm{mg} / \mathrm{dl}$ if atherosclerosis is to be reversed [66]. 
Patients and their families should be given the rationale for the use of medications (if necessary) and repeated tests, as triglycerides and LDLc are the two most important lipids that are amenable to lifestyle changes. Individuals should be made consistently aware that obesity, alcohol use, and diabetes can exacerbate hypertriglyceridemia. As BMI increases, different lipid fractions often lead to irreversible and detrimental changes of the arterial endothelium [67]. LDLc levels, which directly promulgate atherosclerotic plaque formation, are amenable to treatment with reduced saturated and trans fat in the diet [57].

\section{Prognosis}

If untreated, atherosclerosis will lead to excessive mortality in $\sim 40 \%$ of the US population. Since age (i.e., duration of risk factor exposure) is the primary risk factor for ASCVD in adults, implementing atherosclerosis disease prevention in adolescence will likely result in significant reduction of cardiovascular events with aging. In this review we argue that addressing cardiovascular risk factors in the adolescent years may result in an atherosclerosis free heart by adulthood. For example, genetic polymorphisms that result in lower lifetime levels of LDLc demonstrate that prolonged exposure to lower LDLc levels early in life is associated with a substantially greater reduction in the risk of ASCVD then lowering LDLc later in life [68]. In fact, if pediatricians can make this LDLc of $<110$ goal a reality in their patients in conjunction with a reduction of other cardiovascular risk factors, premature atherosclerosis in many adults may become a rarity.

\section{Conclusion}

Atherosclerosis is a pediatric/adult disease beginning during gestation. It progresses throughout childhood and adolescence. Its clinical manifestations primarily occur during the adult years. While current prevention, treatment and management have primarily focused on adult patients, this approach has had minimal effect on reducing the prevalence of cardiovascular disease. Involvement of the pediatrician in the prevention of cardiovascular disease can have a major beneficial effect on eradicating this disease. This result has previously been demonstrated in children with familial homozygous hypercholesterolemia. Identification of the adolescent at risk can be made with appropriate family history, physical exam, and non-invasive testing. ASCVD risk factors need to be addressed and the LDLc concentration needs to be $<110 \mathrm{mg} / \mathrm{dl}$. If diabetes is present, then the LDLc goal should be $<100 \mathrm{mg} / \mathrm{dl}$ [22]. Screening and intervention during early adolescence represents a rational and promising approach for pediatricians to address this public health crisis [69].

\section{Acknowledgements}

Artwork for Figure 1 was done by Christina Klauber. There is no external funding support for this manuscript. 


\section{References}

[1] Fuster, V. (2009) The CVD Paradox: Morality vs. Prevalence. Nature Reviews Cardiology, 6, 669. https://doi.org/10.1038/nrcardio.2009.187

[2] Nissen, S.E., Nicholls, S.J., Sipahi, I., Libby, P., Raichlen, J.S., Ballantyne, C.M., et al. for the ASTEROID Investigators (2006) Effect of Very High-Intensity Statin Therapy on Regression of Coronary Atherosclerosis-The ASTEROID Trial. JAMA, 295, 1556-1565. https://doi.org/10.1001/jama.295.13.jpc60002

[3] Baker, J.L., Olsen, L.W. and Sorensen, T.I.A. (2007) Childhood Body-Mass Index and the Risk of Coronary Heart Disease in Adulthood. New England Journal of Medicine, 357, 2329-2337. https://doi.org/10.1056/NEJMoa072515

[4] Ohlsson, C., Bygdell, M., Sonden, A., Rosengren, A. and Kindblom, J.M. (2016) Association between Excessive BMI Increase during Puberty and Risk of Cardiovascular Mortality in Adult Men: A Population-Based Cohort Study. Lancet, 4, 1017-1024.

[5] Bacha, F., Edmundowicz, D., Sutton-Tyrell, K., Lee, S., Fjayli, H. and Arslanian, S.A. (2014) Coronary Artery Calcification in Obese Youth: What Are the Phenotypic and Metabolic Determinants? Diabetes Care, 37, 2632-2639. https://doi.org/10.2337/dc14-0193

[6] Napoli, C., Glass, C.K., Witztum, J.L., Deutsch, R., D’Armiento, F.P. and Palinski, W. (1999) Influence of Maternal Hypercholesterolaemia during Pregnancy on Progression of Early Atherosclerotic Lesions in Childhood: Fate of Early Lesions in Children (FELIC) Study. Lancet, 354, 1234-1241. https://doi.org/10.1016/S0140-6736(99)02131-5

[7] Napoli, C., D’Armiento, F.P., Mancini, F.P., Postiglione, A., Witztum, J.L., Palumbo, G., et al. (1997) Fatty Streak Formation Occurs in Human Fetal Aortas and Is Greatly Enhanced by Maternal Hypercholesterolemia: Intimal Accumulation of Low Density Lipoprotein and Its Oxidation Precede Monocyte Recruitment into Early Atherosclerotic Lesions. Journal of Clinical Investigation, 100, 2680-2690. https://doi.org/10.1172/JCI119813

[8] Stary, H.C. (1989) Evolution and Progression of Atherosclerotic Lesions in Coronary Arteries of Children and Young Adults. Arteriosclerosis, 9, 119-132.

[9] Zhang, Z.M., Rautaharju, P.M., Prineas, R.J., Rodriguez, C.J., Loehr, L., Rosamond, W.D., et al. (2016) Race and Sex Differences in the Incidence and Prognostic Significance of Silent Myocardial Infarction in the Atherosclerosis Risk in Communities (ARIC) Study. Circulation, 133, 2141-2148. https://doi.org/10.1161/CIRCULATIONAHA.115.021177

[10] Xu, J., Murphy, S.L., Kochanek, K.D. and Arias, E. (2016) Mortality in the United States, 2015. NCHS Data Brief, 267, 1-8.

[11] Gǽde, P., Vedel, P., Larsen, N., Jensen, G.V.H., Parving, H.H. and Pedersen, O. (2003) Multifactorial Intervention and Cardiovascular Disease in Patients with Type 2 Diabetes. The New England Journal of Medicine, 348, 383-393. https://doi.org/10.1056/NEJMoa021778

[12] Berry, J.D., Dyer, A., Cai, X., Garside, D.B., Ning, H., Thomas, A., et al. (2012) Lifetime Risks of Cardiovascular Disease. The New England Journal of Medicine, 366, 321-329. https://doi.org/10.1056/NEJMoa1012848

[13] Deshmukh-Taskar, P., Nicklas, T.A., Morales, M., Yang, S.J., Zakeri, I. and Berenson, G.S. (2006) Tracking of Overweight Status from Childhood to Young Adulthood: The Bogalusa Heart Study. European Journal of Clinical Nutrition, 60, 48-57. https://doi.org/10.1038/sj.ejcn.1602266 
[14] Srinivasan, S.R., Wattigney, W., Webber, L.S. and Berenson, G.S. (1991) Race and Gender Differences in Serum Lipoproteins of Children, Adolescents, and Young Adults-Emergence of an Adverse Lipoprotein Pattern in White Males: The Bogalusa heart study. Preventive Medicine, 20, 671-684. https://doi.org/10.1016/0091-7435(91)90063-A

[15] Bao, W., Srinivasan, S.R., Wattigney, W.A., Bao, W. and Berenson, G.S. (1996) Usefulness of Childhood Low-Density Lipoprotein Cholesterol Level in Predicting Adult Dyslipidemia and Other Cardiovascular Risks: The Bogalusa Heart Study. Archives of Internal Medicine, 156, 1315-1320. https://doi.org/10.1001/archinte.1996.00440110083011

[16] Li, S., Chen, W., Srinivasan, S.R., Bond, M.G., Tang, R. and Urbina, E.M. (2003) Childhood Cardiovascular Risk Factors and Carotid Vascular Changes in Adulthood: The Bogalusa Heart Study. JAMA, 290, 2271-2276.

https://doi.org/10.1001/jama.290.17.2271

[17] Berenson, G.S., Wattigney, W.A., Tracy, R.E., Newman, W.P., Srinivasan, S.R., Webber, L.S., et al. (1992) Atherosclerosis of the Aorta and Coronary Arteries and Cardiovascular Risk Factors in Persons Aged 6 to 30 Years and Studied at Necropsy (The Bogalusa Heart Study). American Journal of Cardiology, 70, 851-858. https://doi.org/10.1016/0002-9149(92)90726-F

[18] McMahan, C.A., Gidding, S.S., Malcom, G.T., Tracy, R.E., Strong, J.P., McGill Jr., H.C., et al. (2006) Pathobiological Determinants of Atherosclerosis in Youth Risk Scores Are Associated with Early and Advanced Atherosclerosis. Pediatrics, 118, 1447-1455. https://doi.org/10.1542/peds.2006-0970

[19] Zoler, M.L. (2016) Internal Medicine News. https://www.mdedge.com/internalmedicinenews/article/113821/cardiology/escs-ne w-lipid-guidelines-keep-ldl-cholesterol

[20] O’Keefe Jr., J.H. (2004) Optimal Low-Density Lipoprotein is 50 to $70 \mathrm{mg} / \mathrm{dl}$ : Lower Is Better and Physiologically Normal. Journal of the American College of Cardiology, 43, 2142-2146. https://doi.org/10.1016/j.jacc.2004.03.046

[21] Gidding, S.S., Daniels, S.R. and Kavey, R.E. (2012) Expert Panel on Cardiovascular Health and Risk Reduction in Youth. Developing the 2011 Integrated Pediatric Guidelines for Cardiovascular Risk Reduction. Pediatrics, 129, e1311-e1319. https://doi.org/10.1542/peds.2011-2903

[22] American Diabetes Association Editors (2017) American Diabetes Association: Standards of Medical Care in Diabetes-2017. Diabetes Care, 40, S4-S5. https://doi.org/10.2337/dc17-S003

[23] Wikipedia Editors. Cholesterol. https://en.wikipedia.org/wiki/cholesterol\#biosynthesis

[24] Santini, S.A., Carrozza, C., Lulli, P., Zuppi, C., CarloTonolo, G. and Musumeci, S. (2003) Atorvastatin Does Not Affect Gonadal or Adrenal Hormones in Type 2 Diabetes with Mild to Moderate Hypercholesterolemia. Journal of Atherosclerosis and Thrombosis, 10, 160-164.

[25] Cholesterol Treatment Trialists' (CTT) Collaboration (2010) Efficacy and Safety of More Intensive Lowering of LDL Cholesterol: A Meta-Analysis of Data from 170,000 Participants in 26 Randomised Trials. The Lancet, 376, 1670-1681. https://doi.org/10.1016/S0140-6736(10)61350-5

[26] Wiviott, S.D., Cannon, C.P., Morrow, D.A., Ray, K.K., Pfeffer, M.A., Braunwald, E. for the PROVE-IT-TIMI 22 Investigators (2005) Can Low-Density Lipoprotein Be Too Low? The Safety and Efficacy of Achieving Very Low Low-density Lipoprotein 
with Intensive Statin Therapy-A PROVE IT-TIMI 22 Substudy. Journal of the American College of Cardiology, 46, 1411-1416. https://doi.org/10.1016/j.jacc.2005.04.064

[27] Ray, K.K., Ginsberg, H.N., Davidson, M.H., Pordy, R., Bessac, L., Minini, P., et al. (2016) Reductions in Atherogenic Lipids and Major Cardiovascular Events: A Pooled Analysis of 10 ODYSSEY Trials Comparing Alirocumab with Control. Circulation, 134, 1931-1943. https://doi.org/10.1161/CIRCULATIONAHA.116.024604

[28] McMurry, M.P., Connor, W.E. and Cerqueira, M.T. (1982) Dietary Cholesterol and the Plasma Lipids and Lipoproteins in the Tarahumara Indians: A People Habituated to a Low Cholesterol Diet after Weaning. The American Journal of Clinical Nutrition, 35, 741-744. https://doi.org/10.1093/ajcn/35.4.741

[29] Ference, B.A., Majeed, F., Penumetcha, R., Flack, J.M. and Brook, R.D. (2015) Effect of Naturally Random Allocation to Lower Low-Density Lipoprotein Cholesterol on the Risk of Coronary Heart Disease Mediated by Polymorphisms in NPC1L1, $H M G C R$, or Both: A 2 x 2 Factorial Mendelian Randomization Study. Journal of the American College of Cardiology, 65, 1552-1561. https://doi.org/10.1016/j.jacc.2015.02.020

[30] Zhao, Z., Tuakli-Wosornu, Y., Lagace, T.A., Kinch, L., Grishin, N.V., Horton, J.D., et al. (2006) Molecular Characterization of Loss-of-Function Mutations in PCSK9 and Identification of a Compound Heterozygote. The American Journal of Human Genetics, 79, 514-523. https://doi.org/10.1086/507488

[31] Raal, F.J., Pilcher, G.J., Panz, V.R., van Deventer, H.E., Brice, B.C., Blom, D.J., et al. (2011) Reduction in Mortality in Subjects with Homozygous Familial Hypercholesterolemia Associated with Advances in Lipid-lowering Therapy. Circulation, 124, 2202-2207. https://doi.org/10.1161/CIRCULATIONAHA.111.042523

[32] Sachdeva, A., Cannon, C.P., Deedwania, P.C., Labresh, K.A., Smith Jr., S.C., Dai, D., et al. (2009) Lipid Levels in Patients Hospitalized with Coronary Artery Disease: An Analysis of 136,905 Hospitalizations in Get with the Guidelines. American Heart Journal, 159, 111-117. https://doi.org/10.1016/j.ahj.2008.08.010

[33] Kavey, R.E., Daniels, S.R., Lauer, R.M., Atkins, D.L., Hayman, L.L. and Taubert, K. (2003) American Heart Association Guidelines for Primary Prevention of Atherosclerotic Cardiovascular Disease Beginning in Childhood. Circulation, 107, 1562-1566. https://doi.org/10.1161/01.CIR.0000061521.15730.6E

[34] Carr, B.R., MacDonald, P.C. and Simpson, E.R. (1980) The Regulation of De Novo Synthesis of Cholesterol in the Human Fetal Adrenal Gland by Low Density Lipoprotein and Adrenocorticotropin. Endocrinology, 107, 1000-1006.

https://doi.org/10.1210/endo-107-4-1000

[35] Carr, B.R., Parker Jr., C.R., Milewich, L., Porter, J.C., MacDonald, P.C. and Simpson, E.R. (1980) The Role of Low Density, High Density, and Very Low Density Lipoproteins in Steroidogenesis by the Human Fetal Adrenal Gland. Endocrinology, 106, 1854-1860. https://doi.org/10.1210/endo-106-6-1854

[36] Nissen, S.E., Tsunoda, T., Tuzcu, E.M., Schoenhagen, P., Cooper, C.J., Yasin, M., et al. (2003) Effect of Recombinant ApoA-I Milano on Coronary Atherosclerosis in Patients with Acute Coronary Syndromes. JAMA, 290, 2292-2300. https://doi.org/10.1001/jama.290.17.2292

[37] Castelli, W.P. (1986) The Triglyceride Issue: A View from Framingham. American Heart Journal, 112, 432-437. https://doi.org/10.1016/0002-8703(86)90296-6

[38] Libby, P. (2002) Atherosclerosis: The New View. Scientific American, 286, 46-55. https://doi.org/10.1038/scientificamerican0502-46 
[39] Landmesser, U., Hornig, B. and Drexler, H. (2004) Endothelial Function: A Critical Determinant in Atherosclerosis? Circulation, 109, II-27-II-33. https://doi.org/10.1161/01.CIR.0000129501.88485.1f

[40] Ridker, P.M., Rifai, N., Pfeffer, M.A., Sacks, F.M., Moye, L.A. and Goldman, S. (1998) Inflammation, Pravastatin, and the Risk of Coronary Events after Myocardial Infarction in Patients with Average Cholesterol Levels. Circulation, 98, 839-844. https://doi.org/10.1161/01.CIR.98.9.839

[41] Rohatgi, A., Khera, A., Berry, J.D., Givens, E.G., Ayers, C.R., Wedin, K.E., et al. (2014) HDL Cholesterol Efflux Capacity and Incident Cardiovascular Events. The New England Journal of Medicine, 371, 2383-2393. https://doi.org/10.1056/NEJMoa1409065

[42] Nagano, Y., Arai, H. and Kita, T. (1991) High Density Lipoprotein Loses Its Effect to Stimulate Efflux of Cholesterol from Foam Cells after Oxidative Modification (Atherosclerosis/Regression/Macrophage). Proceedings of the National Academy of Sciences of the United States of America, 88, 6457-6461. https://doi.org/10.1073/pnas.88.15.6457

[43] AIM-HIGH Investigators (2011) Niacin in Patients with Low HDL Cholesterol Levels Receiving Intensive Statin Therapy. The New England Journal of Medicine, 365, 2255-2267. https://doi.org/10.1056/NEJMoa1107579

[44] Schade, D.S., Cavanaugh, B., Ramo, B. and Eaton, R.P. (2016) The Application of the LDL Principle. World Journal of Cardiovascular Diseases, 6, 109-125. https://doi.org/10.4236/wjcd.2016.65012

[45] Daniels, S.R. (2001) Cardiovascular Disease Risk Factors and Atherosclerosis in Children and Adolescents. Current Atherosclerosis Reports, 3, 479-485. https://doi.org/10.1007/s11883-001-0038-3

[46] Twig, G., Yaniv, G., Levine, H., Leiba, A., Goldberger, N., Derazne, E., et al. (2016) Body-Mass Index in 2.3 Million Adolescents and Cardiovascular Death in Adulthood. The New England Journal of Medicine, 374, 2430-2440. https://doi.org/10.1056/NEJMoa1503840

[47] Gidding, S.S. (2016) Why Cholesterol Testing in Children and Adolescents Matters. JAMA Cardiology, 1, 859-861. https://doi.org/10.1001/jamacardio.2016.2871

[48] Daniels, S.R., Greer, F.R. and Committee on Nutrition (2008) Lipid Screening and Cardiovascular Health in Childhood. Pediatrics, 122, 198-208. https://doi.org/10.1542/peds.2008-1349

[49] Alonso, R., Andres, E., Mata, N., Fuentes-Jimenez, F., Badimon, L., Lopez-Miranda, J., et al. (2014) Lipoprotein(a) Levels in Familial Hypercholesterolemia. Journal of the American College of Cardiology, 63, 1982-1989. https://doi.org/10.1016/j.jacc.2014.01.063

[50] Kullo, D.K. (2009) Evolutionary Genetics of Coronary Heart Disease. Circulation, $19,459-467$.

[51] O’Leary, D.H. and Polak, J.F. (2002) Intima-Media Thickness: A Tool for Atherosclerosis Imaging and Event Prediction. American Journal of Cardiology, 90, 18L-21L. https://doi.org/10.1016/S0002-9149(02)02957-0

[52] Sorof, J.M., Alexandrov, A.V., Cardwell, G. and Portman, R.J. (2003) Carotid Artery Intimal-Medial Thickness and Left Ventricular Hypertrophy in Children with Elevated Blood Pressure. Pediatrics, 111, 61-66. https://doi.org/10.1542/peds.111.1.61

[53] Wilson, P.W.F., Hoeg, J.M., D’Agostino, R.B., Silbershatz, H., Belanger, A.M., Poehlmann, H., et al. (1997) Cumulative Effects of High Cholesterol Levels, High 
Blood Pressure, and Cigarette Smoking on Carotid Stenosis. The New England Journal of Medicine, 337, 516-522. https://doi.org/10.1056/NEJM199708213370802

[54] Eaton, R.P., Burge, M.R., Comerci, G., Cavanaugh, B., Ramo, B. and Schade, D.S. (2017) Abnormal Coronary Artery Calcium Scans in Asymptomatic Patients. American Journal of Medicine, 130, 394-397. https://doi.org/10.1016/j.amjmed.2016.10.006

[55] Urbina, E.M., Williams, R.V., Alpert, B.S., Collins, R.T., Daniels, S.R., Hayman, L., et al. (2009) Noninvasive Assessment of Subclinical Atherosclerosis in Children and Adolescents: Recommendations for Standard Assessment for Clinical Research: A Scientific Statement from the American Heart Association. Hypertension, 54, 919-950. https://doi.org/10.1161/HYPERTENSIONAHA.109.192639

[56] Morrison, K.M., Dyal, L., Conner, W., Helden, E., Newkirk, L., Yusuf, S., et al. (2010) Cardiovascular Risk Factors and Non-invasive Assessment of Subclinical Atherosclerosis in Youth. Atherosclerosis, 208, 501-505. https://doi.org/10.1016/j.atherosclerosis.2009.07.034

[57] Hu, F.B. and Willett, W.C. (2002) Optimal Diets for Prevention of Coronary Heart Disease. JAMA, 288, 2569-2578. https://doi.org/10.1001/jama.288.20.2569

[58] Kusters, D.M., Avis, H.J., de Groot, E., Wijburg, F.A., Kastelein, J.J., Wiegman, A., et al. (2014) Ten-Year Follow-Up after Initiation of Statin Therapy in Children with Familial Hypercholesterolemia. JAMA, 312, 1055-1057. https://doi.org/10.1001/jama.2014.8892

[59] Braamskamp, M.J.A.M., Kastelein, J.J.P., Kusers, D.M., Hutten, B.A. and Wiegman, A. (2016) Statin Initiation during Childhood in Patients with Familial Hypercholesterolemia: Consequences for Cardiovascular Risk. Journal of the American College of Cardiology, 67, 455-456. https://doi.org/10.1016/j.jacc.2015.11.021

[60] Franc, S., Dejager, S., Bruckert, E., Chauvenet, M., Giral, P. and Turpin, G. (2003) A Comprehensive Description of Muscle Symptoms Associated with Lipid-Lowering Drugs. Cardiovascular Drugs and Therapy, 17, 459-465. https://doi.org/10.1023/B:CARD.0000015861.26111.ab

[61] Sattar, N., Preiss, D., Murray, H.M., Welsh, P., Buckley, B.M., de Craen, A.J., et al. (2010) Statins and Risk of Incident Diabetes: A Collaborative Meta-Analysis of Randomized Statin Trials. The Lancet, 375, 735-742. https://doi.org/10.1016/S0140-6736(09)61965-6

[62] Clauss, S., Wai, K.M., Kavey, W. and Kuehl, K. (2009) Ezetimibe Treatment of Pediatric Patients with Hypercholesterolemia. Journal of Pediatrics, 154, 869-872. https://doi.org/10.1016/j.jpeds.2008.12.044

[63] Sudhop, T. (2002) Inhibition of Intestinal Cholesterol Absorption by Ezetimibe in Humans. Circulation, 106, 1943-1948. https://doi.org/10.1161/01.CIR.0000034044.95911.DC

[64] Selvin, E., Steffes, M.W., Zhu, H., Matsushita, K., Wagenknecht, L., Pankow, J., et al. (2010) Glycated Hemoglobin, Diabetes, and Cardiovascular Risk in Nondiabetic Adults. The New England Journal of Medicine, 362, 800-811. https://doi.org/10.1056/NEJMoa0908359

[65] Wadwa, R.P., Kinney, G.L., Maahs, D.M., Snell-Bergeon, J., Hokanson, J.E., Garg, S.K., et al. (2005) Awareness and Treatment of Dyslipidemia in Young Adults with Type 1 Diabetes. Diabetes Care, 28, 1051-1056. https://doi.org/10.2337/diacare.28.5.1051

[66] Shepherd, J., Barter, P., Carmena, R., Deedwania, P., Fruchart, J.C., Haffner, S., et al. (2006) Effect of Lowering LDL Cholesterol Substantially below Currently Recom- 
mended Levels in Patients with Coronary Heart Disease and Diabetes. Diabetes Care, 29, 1220-1226. https://doi.org/10.2337/dc05-2465

[67] Tirosh, A., Shai, I., Afek, A., Dubnov-Raz, G., Ayalon, N., Gordon, B., et al. (2011) Adolescent BMI Trajectory and Risk of Diabetes versus Coronary Disease. The New England Journal of Medicine, 364, 1315-1325.

https://doi.org/10.1056/NEJMoa1006992

[68] Ference, B.A., Yoo, W., Alesh, I., Mahajan, N., Mirowska, K.K., Mewada, A., et al. (2012) Effect of Long-Term Exposure to Lower Low-Density Lipoprotein Cholesterol Beginning Early in Life on the Risk of Coronary Heart Disease: A Mendelian Randomization Analysis. Journal of the American College of Cardiology, 60, 2631-2639. https://doi.org/10.1016/j.jacc.2012.09.017

[69] Strong, J.P., Malcom, G.T., McMahan, C.A., Tracy, R.E., Newman, W.P., Herderick, E.E., et al. (1999) Prevalence and Extent of Atherosclerosis in Adolescents and Young Adults: Implications for Prevention from the Pathobiological Determinants of Atherosclerosis in Youth Study. JAMA, 281, 727-735.

https://doi.org/10.1001/jama.281.8.727 